\title{
PENGARUH PENGOLAHAN TANAH DAN PEMBERIAN MULSA BAGAS TERHADAP BIOMASSA KARBON MIKROORGANISME TANAH (C-MIK) PADA LAHAN PERTANAMAN TEBU PT GMP TAHUN KETIGA
}

\author{
Eko Ari Widodo, Ainin Niswati, Sri Yusnaini \& Henrie Buchori \\ Jurusan Agroteknologi, Fakultas Pertanian Universitas Lampung, \\ J1. Prof. SoemantriBrodjonegoro, No. 1, Bandar Lampung 35145. \\ Email: ekoariwidodo1990@gmail.com
}

\begin{abstract}
ABSTRAK
Penelitian ini bertujuan untuk mempelajari pengaruh aplikasi mulsa bagas dan sistem pengolahan tanah pada lahan pertanaman tebu (Saccharum officinarum L.) terhadap biomasa karbon mikroorganisme tanah (C-mik) di PT Gunung Madu Plantations, Lampung Tengah tahun ketiga. Penelitian ini dilaksanakan pada bulan Maret 2014. Percobaan dilakukan di lahan pertanaman tebu PT Gunung Madu Plantations dengan perlakuan sistem olah tanah dan aplikasi limbah pabrik gula jangka panjang dari tahun 2010 sampai dengan tahun 2020. Analisis biomassa karmon mikroorganisme (C-mik) dilakukan di Laboratorium Biologi Ilmu Tanah dan analisis contoh tanah dilakukan di Laboratorium Ilmu Tanah, Fakultas Pertanian, Unversitas Lampung. Penelitian ini dilakukan dengan menggunakan rancangan petak terbagi dan disusun secara split plot dengan 5 ulangan dan 4 perlakuan. Sebagai petak utama adalah perlakuan sistem olah tanah $(\mathrm{T})$ yaitu: $\mathrm{T}_{0}=\tan$ a olah tanah, $\mathrm{T}_{1}=$ olah tanah intensif. Sedangkan anak petak dalam penelitian ini adalah penggunaan limbah pabrik gula (M) yaitu: $\mathbf{M}_{0}=$ tanpa mulsa, $\mathbf{M}_{1}=$ mulsa bagas 80 ton ha 1. Data yang diperoleh dianalisis dengan sidik ragam yang sebelumnya telah diuji homogenitas ragamnya dengan Uji Bartlett dan aditivitasnya dengan Uji Tukey. Rata-rata nilai tengah diuji dengan uji BNT pada taraf $1 \%$ dan 5\%. Untuk mengetahui hubungan antara biomassa karbon mikroorganisme tanah dengan $\mathrm{C}$-organik, $\mathrm{pH}$, kadar air tanah, dan suhu tanah dilakukan uji korelasi. Hasil penelitian menunjukkan bahwa perlakuan sistem olah tanah dan pemberian mulsa bagas tidak berpengaruh nyata pada biomassa karbon mikroornisme tanah (C-mik) pada masing - masing waktu pengamatan.
\end{abstract}

Kata kunci: Biomassa karbon mikroorganisme (C-mik), mulsa bagas, sistem olah tanah

\section{PENDAHULUAN}

Tebu (Saccharum officinarum L.) adalah tanaman yang ditanam untuk bahan baku gula. Tanaman ini hanya dapat tumbuh di iklim tropis dan merupakan tanaman jenis rumput-rumputan. Peningkatan jumlah penduduk Indonesia menyebabkan kebutuhan gula semakin meningkat. Indonesia merupakan salah satu negara penghasil gula di dunia, tetapi Indonesia mengalami kekurangan akibat konsumsi gula yang lebih tinggi dibandingkan dengan produksinya. PT. Gunung Madu Plantation telah mengusahakan perkebunan tebu sejak tahun 1975 yang terus menerus melakukan pengolahan tanah secara intensif, penggunaan bahan-bahan kimia pertanian seperti pupuk, dan pestisida dalam meningkatkan produksi gula. Aplikasi bahan organik berbasis tebu (bagas, blotong, dan abu) yang dilakukan untuk mempertahankan kesuburan tanah dilakukan sejak tahun 2004 (PT. GMP, 2009).

Salah satu usaha untuk menjaga kelestarian mikroorganisme di dalam tanah diperlukan penanganan olah tanah konservasi (OTK) yang berwawasan ramah lingkungan. Sistem OTK mampu memperbaiki kesuburan tanah lebih baik dari pada sistem OTI umumnya pada tanah ultisol. OTK terdiri dari dua sistem olah tanah yaitu olah tanah minimum (OTM) gulma dibabat dengan menggunakan alat mekanis kemudian dikembalikan kelahan pertanaman dan tanpa olah tanah (TOT) dengan mengendalikan gulma menggunakan herbisida, gulma dibiarkan mati dan digunakan sebagai mulsa (Utomo, 2006).

Penerapan sistem tanpa olah tanah diharapkan mampu memperbaiki kualitas tanah dengan meningkatkan keanekaragaman biota dalam tanah, memperbaiki struktur tanah, meningkatkan kandungan C-organik tanah, dan meningkatkan kandungan karbon melalui pengikatan karbon dalam tanah. Selain itu sistem tanpa olah tanah paling baik dilakukan karna mampu menekan terjadinya aliran permukaan yang dapat menghilangkan adanya pencucian bahan organik (Widiono, 2005).

Mikroorganisme tanah memegang peranan penting dalam berbagai proses di dalam tanah baik peran 
dalam siklus energi, siklus hara, pembentukan agregat tanah, dan dalam menentukan kesehatan tanah (suppressive/conducive). Tanah dikatakan subur bila memiliki kandungan dan keragaman biologi yang tinggi, dan berperan untuk mengetahui jumlah biomassa karbon mikroorganisme (C-mik) tanah dalam pendugaan biomassa mikroorganisme tanah dengan memperhatikan sistem olah tanah, serta bahan organik tanah dalam pemberian mulsa. Upaya untuk meningkatkan kesuburan tanah salah satunya dengan penambahan bahan organik. Pemberian bahan organik tanah dengan tujuan pemberdayaan sumber hayati tanah untuk meningkatkan kesuburan tanah potensial perlu diupayakan. Selain memerlukan dosis yang lebih rendah juga dapat meningkatkan konservasi bahan organik tanah dan menekan emisi $\mathrm{CO}_{2}$ ( Subowo, 2010). Penelitian ini bertujuan untuk mempelajari pengaruh aplikasi mulsa bagas dan sistem pengolahan tanah pada lahan pertanaman tebu (Saccharum officinarum L.) terhadap biomasa karbon mikroorganisme tanah (C-mik).

\section{BAHAN DAN METODE}

Penelitian ini dilaksanakan pada bulan Maret 2014 sampai dengan bulan Juni 2014. Percobaan dilakukan di lahan pertanaman tebu PT. GMP dengan perlakuan sistem olah tanah dan aplikasi mulsa bagas jangka panjang dari tahun 2010 sampai dengan tahun 2020. Penelitian yang dilakukan saat ini merupakan pertanaman tebu yang berasal dari tanaman tebu sebelumnya (ratoon cane) tahun ketiga yang analisisnya dilakukan di Laboratorium Ilmu Tanah, Fakultas Pertanian Universitas Lampung. Alat yang akan digunakan adalah bor belgi, kantung plastik, alat tulis, timbangan, lakban, toples, desikator, biuret, dan alatalat laboratorium lainnya untuk analisis tanah. Bahanbahan kimia yang digunakan untuk analisis C-mik dengan metode fumigasi-inkubasi (Jenkinson dan Powlson, 1976) adalah $\mathrm{CHCL}_{3} \mathrm{KOH}$, dan akuades. Sedangkan untuk analisis $\mathrm{C}$ organik tanah menggunakan metode (Walkley dan Black), dan $\mathrm{pH}$ tanah.

Penelitian ini dilakukan dengan menggunakan rancangan petak terbagi dan disusun secara split plot dengan 5 ulangan dan 4 perlakuan. Sebagai petak utama adalah perlakuan sistem olah tanah $(\mathrm{T})$ yaitu: $\mathrm{T}_{0}=\operatorname{tanpa}$ olah tanah, $\mathrm{T}_{1}=$ olah tanah intensif. Sedangkan anak petak dalam penelitian ini adalah penggunaan limbah pabrik gula (M) yaitu: $M_{0}=$ tanpa mulsa, $M_{1}=$ mulsa bagas 80 ton $\mathrm{ha}^{-1}$. Data yang diperoleh diuji homogenitas ragamnya dengan Uji Bartlett dan aditifitasnya dengan Uji Tukey. Setelah asumsi dipenuhi, yaitu ragam homogen dan aditif dengan dilakukan analisis ragam pada taraf $1 \%$ dan $5 \%$. Untuk membedakan nilai tengah dilakukan dengan uji BNT pada taraf 5\%, kemudian untuk mengetahui hubungan antara C-mik dengan $\mathrm{pH}$ tanah, C-organik, suhu tanah, dan kadar air tanah dilakukan uji korelasi.

Pengambilan contoh tanah diambil dengan menggunakan bor tanah dari 12 titik pada masing-masing plot percobaan dengan kedalaman $20 \mathrm{~cm}$ dan kemudian dikompositkan. Pengambilan contoh tanah diambil secara melingkar dengan titik tengah plot sebagai titik pusatnya, empat titik berjarak $3 \mathrm{~m}$ dari titik pusat dan delapan titik berjarak $3 \mathrm{~m}$ dari titik pertama (Susilo dan Karyanto, 2005 yang dikutip oleh Sucipto, 2011). Pengambilan contoh tanah awal dilakukan pada bulan April 2014. Pengambilan contoh tanah kedua dilakukan pada pertengahan bulan Juli 2014. Pengambilan contoh tanah diambil dari masing - masing plot sebanyak 500 g secara komposit dari 12 titik sampel menggunakan bor tanah sedalam $20 \mathrm{~cm}$, kemudian dimasukan kedalam kantong plastik dan diberi label (perlakuan, kelompok, hari, dan tanggal). Setelah itu tanah dimasukan ke dalam lemari pendingin pada suhu $4^{\circ} \mathrm{C}$ dikarenakan análisis tanah tidak dilakukan secara langsung setelah pengambilan contoh tanah.

Biomassa karbon mikroorganisme tanah (C-mik) dengan menggunakan metode modifikasi fumigasiinkubasi (Jenkinson dan Powlson 1976). Proses pelaksanaan analisis yaitu tanah lembab (setara dengan 100 gram berat kering oven) ditempatkan dalam gelas beaker $100 \mathrm{ml}$. kemudian tanah difumigasi menggunakan kloroform $\left(\mathrm{CHCl}_{3}\right)$ sebanyak $30 \mathrm{ml}$ dalam desikator yang telah diberi tekanan $50 \mathrm{~cm} \mathrm{Hg}$ selama 1 jam dimatikan sistem kerjanya setelah tanah dibebaskan dari $\mathrm{CHCl}_{3}$ dibawah tekanan $30 \mathrm{~cm} \mathrm{Hg}$ dan dibiarkan di dalam desikator sampai 2 hari terhitung dari 1 jam masa kerja desikator.

Setelah tanah difumigasi selama 2 hari, kemudian tanah yang telah difumigasi dan telah bebas $\mathrm{CHCL}_{3}$

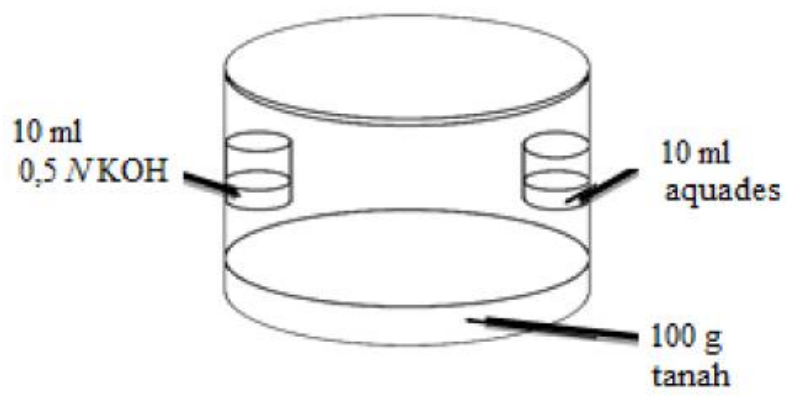

Gambar 1. Skema pelaksanaan inkubasi tanah penentuan kadar $\mathrm{KOH}$ di dalam toples yang selanjutnya untuk keperluan titrasi 
dimasukkan ke dalam toples berukuran 1 liter bersama dua botol film, satu botol film berisi $10 \mathrm{ml} \mathrm{KOH} \mathrm{0,5} \mathrm{N}$ dan satu botol film berisi $10 \mathrm{ml}$ aquades (Gambar 1). Kemudian ditambahkan $5 \mathrm{~g}$ tanah inokulan (tanah segar) yang telah dikeluarkan dari lemari pendingin selama setengah hari $( \pm 5$ jam) sebagai proses aklimatisasi. Kedua sampel tanah diinkubasi pada suhu $25^{\circ} \mathrm{C}$ selama 10 hari. Kuantitas $\mathrm{C}-\mathrm{CO}_{2}$ yang diserap dalam alkali ditentukan dengan titrasi. Kemudian indikator phenolphtalein ditambahkan sebanyak 2 tetes pada beaker berisi $\mathrm{KOH}$ dan dititrasi dengan $\mathrm{HCl} 0,1 N$ hingga warna ping menjadi bening. Selanjutnya dititrasi lagi dengan $\mathrm{HCl}$ setelah ditambahkan 2 tetes metil orange hingga warna kuning berubah menjadi ping, dan jumlah $\mathrm{HCl}$ yang digunakan dicatat.

Reaksi kimia pengikatan $\mathrm{CO}_{2}$ untuk proses titrasi:

1. Reaksi pengikatan $\mathrm{CO}_{2}$ (inkubasi selama 10 hari)

$$
2 \mathrm{KOH}+\mathrm{CO}_{2} \rightarrow \mathrm{K}_{2} \mathrm{CO}_{3}+\mathrm{H}_{2} \mathrm{O}
$$

2. Perubahan warna menjadi tidak berwarna (indikatar penolphtalin)

$$
\mathrm{K}_{2} \mathrm{CO}_{3}+\mathrm{HCl} \rightarrow \mathrm{KHCO}_{3}+\mathrm{KCl}
$$

3. Perubahan warna kuning menjadi pink (indikator metil orange)

$$
\mathrm{KHCO}_{3}+\mathrm{HCl} \rightarrow \mathrm{KCl}+\mathrm{H}_{2} \mathrm{O}+\mathrm{CO}_{2}
$$

Untuk tanah non-fumigasi menggunakan 100 gram tanah bobot kering oven, dimasukkan ke dalam toples berukuran 1 liter bersama dua botol film, satu botol film berisi $10 \mathrm{ml} \mathrm{KOH} 0,5 N$ dan satu botol film berisi $10 \mathrm{ml}$ aquades, tanpa penambahan tanah inokulan. Toples tersebut ditutup dengan menggunakan lakban dan diinkubasi pada suhu $25^{\circ} \mathrm{C}$ selama 10 hari. Sedangkan untuk kontrol atau blangko dimasukkan kedalam toples berukuran 1 liter, satu botol film yang berisi $10 \mathrm{ml}$ aquades dan satu botol film berisi $10 \mathrm{ml} \mathrm{KOH} 0,5 \mathrm{~N}$. Toples ditutup menggunakan lakban dan diinkubasi dengan suhu $25^{\circ} \mathrm{C}$ selama 10 hari. Pada akhir masa inkubasi non fumigasi maupun kontrol kuantitas $\mathrm{C}-\mathrm{CO}_{2}$ yang dihasilkan dalam alkali ditentukan sama dengan contoh tanah fumigasi (titrasi).

Biomassa mikroorganisme tanah dihitung dengan rumus akhir:

$\mathrm{mg} \mathrm{CO}-\mathrm{C} \mathrm{kg}^{-1} 10$ hari $=(\mathrm{a}-\mathrm{b} \times \mathrm{t} \times 120) / \mathrm{n}$

$\mathrm{C}-\mathrm{mik}=\left\{\left(\mathrm{mg} \mathrm{CO}_{2}-\mathrm{C} \mathrm{kg}^{-1} 10 \text { hari }\right)_{\text {fumigasi }}\right.$ - $^{-}$

$$
\text { (mg CO} \left.2-\mathrm{Ckg}^{-1} 10 \text { hari }\right)_{\text {nonfumigasi }} / \mathrm{Kc}
$$

Keterangan :

$\mathrm{a}=\mathrm{ml} \mathrm{HCl}$ untuk contoh tanah

$\mathrm{n}=$ waktu inkubasi (hari)

$\mathrm{b}=\mathrm{ml} \mathrm{HCl}$ untuk blanko

$\mathrm{t}=$ normalitas $\mathrm{HCl}$

\section{HASIL DAN PEMBAHASAN}

Hasil penelitian Tabel 1 menunjukkan bahwa perlakuan olah tanah serta pemberian mulsa bagas tidak berpengaruh nyata terhadap biomassa karbon

Tabel 1. Ringkasan uji signifikasi pengaruh olah tanah dan aplikasi mulsa bagas terhadap C-mik pada 9 dan 12 bulan setelah tanam (BST).

\begin{tabular}{lcc}
\hline \multirow{2}{*}{$\begin{array}{c}\text { Sumber } \\
\text { Keragaman }\end{array}$} & \multicolumn{2}{c}{ Waktu Pengamatan } \\
\cline { 2 - 3 } & $9 \mathrm{BST}$ & $12 \mathrm{BST}$ \\
\hline Kelompok & tn & tn \\
Olah Tanah (PU) & tn & tn \\
Mulsa(AP) & tn & tn \\
Interaksi & tn & tn \\
\hline
\end{tabular}

Keterangan: $\mathrm{tn}=$ tidak berbeda nyata, $\mathrm{PU}=$ Petak Utama, AP = Anak Petak

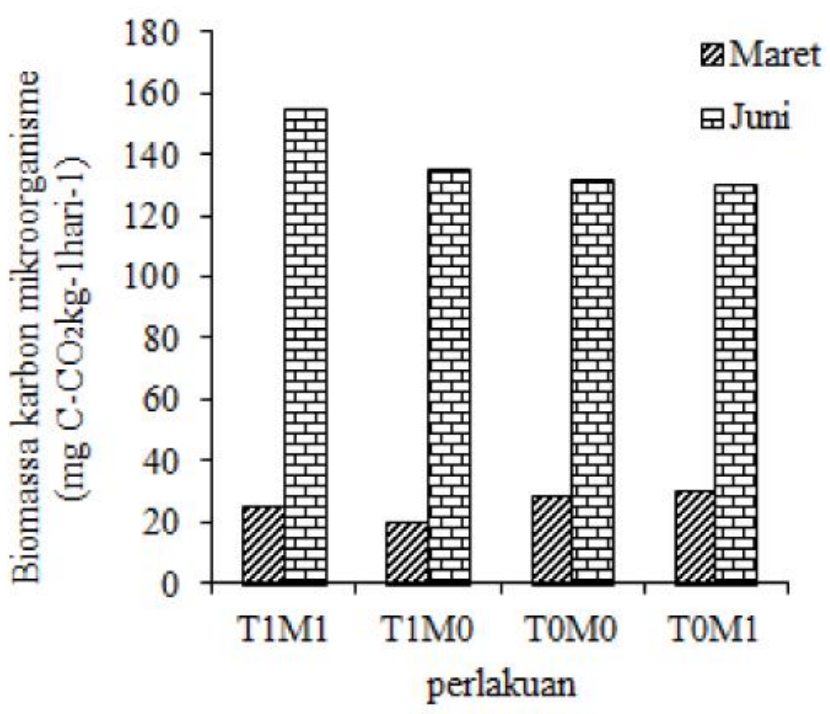

Gambar 2. Biomassa karbon mikroorganisme tanah (mg C- $\mathrm{CO}_{2} \mathrm{~kg}^{-1}$ hari ${ }^{-1}$ ) di Pertanaman tebu PT GMP pada pengamatan 9 BST dan 12 BST 2014. $\left(\mathrm{T}_{0}=\right.$ tanpa olah tanah, $\mathrm{T}_{1}=$ olah tanah intensif, $\mathrm{M}_{0}=$ tanpa mulsa bagas, $\mathrm{M}_{1}=$ mulsa bagas $80 \mathrm{t} \mathrm{ha}^{-1}$, tongkat diatas menunjukkan standar deviasi) 
mikroorganisme tanah (C-mik). Hal ini sejalan dengan penelitian Pratiwi (2013) yang menyatakan bahwa dalam kurun waktu yang singkat penerapan perlakuan sistem olah tanah belum memperlihatkan pengaruh yang nyata terhadap kandungan bahan organilk tanah.

Gambar 2 menunjukkan bahwa perlakuan sistem tanpa olah tanah dan pemberian mulsa bagas tidak berbeda nyata terhadap C-mik, tetapi C-mik tanah lebih tinggi pada pengamatan 12 BST dibandingkaan pada pengamatan 9 BST.
Tabel 2 menunjukan bahwa perlakuan sistem olah tanah berpengaruh nyata terhadap C-organik pada 9 BST dan 12 BST, serta kadar air pada 12 BST. Hal ini di duga karena keberadaan mikroorganisme di dalam tanah dapat memperpaiki proses dekomposisi bahan organik dan memanfaatkan bahan organik tanah sebagai sumber nutrisi.

Tabel 3 menunjukkan bahwa perlakuan pada sistem tanpa olah tanah memiliki kandungan C-organik dan kadar air lebih tinggi dari pada olah tanah intensif

Tabel 2. Analisis ragam pengaruh sistem olah tanah dan pemberian mulsa bagas terhadap biomassa karbon mikroorganisme tanah (C-mik) di Pertanaman tebu PT GMP pada pengamatan 9 BST dan 12 BST 2014

\begin{tabular}{|c|c|c|c|c|c|c|c|c|}
\hline \multirow{3}{*}{ Sumber keragaman } & \multicolumn{8}{|c|}{ Variabel pengamatan } \\
\hline & \multicolumn{2}{|c|}{ C-organik (\%) } & \multicolumn{2}{|c|}{$\mathrm{pH}\left(\mathrm{H}_{2} \mathrm{O}\right)$} & \multicolumn{2}{|c|}{ Kadar Air (\%) } & \multicolumn{2}{|c|}{ Suhu $\left({ }^{\circ} \mathrm{C}\right)$} \\
\hline & $9 \mathrm{BST}$ & $12 \mathrm{BST}$ & $9 \mathrm{BST}$ & $12 \mathrm{BST}$ & $9 \mathrm{BST}$ & $12 \mathrm{BST}$ & $9 \mathrm{BST}$ & $12 \mathrm{BST}$ \\
\hline Kelompok & tn & $\operatorname{tn}$ & tn & $\operatorname{tn}$ & $\operatorname{tn}$ & $*$ & tn & tn \\
\hline $\begin{array}{c}\text { Pengolahan Tanah } \\
\text { (PU) }\end{array}$ & $*$ & $* *$ & tn & tn & tn & $*$ & tn & tn \\
\hline Mulsa (AP) & tn & $\operatorname{tn}$ & $\operatorname{tn}$ & $\operatorname{tn}$ & $\operatorname{tn}$ & $\operatorname{tn}$ & tn & tn \\
\hline Interaksi & $\operatorname{tn}$ & $\operatorname{tn}$ & $\operatorname{tn}$ & $\operatorname{tn}$ & $\operatorname{tn}$ & $\operatorname{tn}$ & $\operatorname{tn}$ & $\operatorname{tn}$ \\
\hline
\end{tabular}

Keterangan: ${ }^{\mathrm{tn}}=$ Tidak berbeda nyata pada taraf nyata $5 \%$ dan $1 \% ; *=$ Berbeda nyata pada taraf $5 \%$; $* *$ = Berbeda nyata pada taraf $5 \%$ dan $1 \%$; PU = Petak Utama; AP = Anak Petak

Tabel 3. Uji BNT perlakuan sistem olah tanah terhadap kadar C-organik pada 9 BST dan 12 BST

\begin{tabular}{lcccc}
\hline \multirow{1}{*}{ Perlakuan olah tanah } & \multicolumn{2}{c}{ Kadar C-organik $(\%)$} & \multicolumn{2}{c}{ Kadar Air $(\%)$} \\
\cline { 2 - 5 } & 9 BST & $12 \mathrm{BST}$ & $9 \mathrm{BST}$ & $12 \mathrm{BST}$ \\
\hline Olah tanah intensif (OTI) & $1,22 \mathrm{a}$ & $1,22 \mathrm{a}$ & $17,29 \mathrm{a}$ & $19,15 \mathrm{a}$ \\
Tanpa olah tanah (TOT) & $1,40 \mathrm{~b}$ & $1,40 \mathrm{~b}$ & $20,45 \mathrm{~b}$ & $22,69 \mathrm{~b}$ \\
\hline BNT 5\% & 0,05 & 0,05 & 1,03 & 0,90 \\
\hline
\end{tabular}

Keterangan: Angka-angka yang diikuti huruf yang sama pada kolom yang sama tidak berpengaruh nyata berdasarkan uji BNT pada taraf $5 \%$

Tabel 4. Hasil uji korelasi antara beberapa sifat tanah (C-organik, $\mathrm{pH}$ tanah, kadar air tanah, dan suhu tanah) pada 9 dan 12 BST dengan C-mik (mg C-CO $\mathrm{kg}^{-1}$ hari ${ }^{-1}$ ).

\begin{tabular}{lcc}
\hline \multirow{2}{*}{ Variabel } & \multicolumn{2}{c}{ Biomassa Karbon Mikroorganisme $\left(\mathrm{mg} \mathrm{C}-\mathrm{CO}_{2} \mathrm{~kg}^{-1} \mathrm{hari}^{-1}\right)$} \\
\cline { 2 - 3 } & \multicolumn{2}{c}{ Nilai r } \\
\cline { 2 - 3 } & $9 \mathrm{BST}$ & $12 \mathrm{BST}$ \\
\hline C-organik & $0,19^{\mathrm{tn}}$ & $0,07^{\mathrm{tn}}$ \\
Kadar air & $0,28^{\mathrm{tn}}$ & $0,00^{\mathrm{tn}}$ \\
Reaksi tanah $(\mathrm{pH})$ & $0,43^{\mathrm{tn}}$ & $0,09^{\mathrm{tn}}$ \\
Suhu & $0,34^{\mathrm{tn}}$ & $0,06^{\mathrm{tn}}$ \\
\hline
\end{tabular}

Keterangan: ${ }^{\mathrm{tn}}=$ tidak berbeda nyata pada taraf $5 \%$ dan $1 \%$. 
baik pada 9 BST maupun 12 BST. Sedangkan untuk uji korelasi pada Tabel 4 menunjukkan bahwa C-organik, $\mathrm{pH}$ tanah, kadar air tanah, dan suhu tanah tidak berbeda nyata terhadap kandungan biomassa karbon mikroorganisme tanah.

\section{KESIMPULAN}

Berdasarkan hasil penelitian dapat disimpulkan bahwa sistem pengolahan tanah dan pemberian mulsa bagas pada pertanaman tebu tidak berpengaruh terhadap C-mik, baik pada 9 BST dan 12 BST. Pada sistem tanpa olah tanah (TOT) C-organik dan kadar air lebih tinggi dari pada olah tanah intensif (OTI) pada 9 BST dan 12 BST. Tidak terdapat korelasi antara C-organik, kadar air, $\mathrm{pH}$, dan suhu dengan $\mathrm{C}$-mik.

\section{DAFTAR PUSTAKA}

Jenkinson, D.S. dan D.S. Powlson. 1976. The Effect of Biocidal treatments on Metabolism in soil$V$. Fumigation with chloroform. Soil. Biol. Biochem. 8: 209-213.

Lubis. K. S. 2007. Aplikasi Suhu dan Aliran Panas Tanah. Fakultas Pertanian Sumatra Utara. Medan.
Pratiwi, T. D. 2013. Pengaruh pengolahan tanah dan pemberian mulsa bagas terhadap kandungan biomassa karbon mikroorganisme tanah (Cmik) pada lahan pertanaman tebu tahun kedua. Skripsi. Universitas Lampung. $52 \mathrm{hlm}$.

PT GMP. 2009. Pengolahan Tanah. Available online at www.Gunungmadu.co.id., [29 Januari 2014].

Subowo, G. 2010. Strategi efisiensi penggunaan bahan organik untuk kesuburan dan produktivitas tanah melalui pemberdayaan sumberdaya hayati tanah. Jurnal Sumber Daya Lahan. 4: 15-27.

Sucipto. 2011. Pengaruh Sistem Olah Tanah Dan Aplikasi Mulsa Bagas Terhadap Biomassa Karbon Mikroorganisme Tanah (C-Mik) Pada Lahan Pertanaman Tebu PT Gunung Madu Plantation. Skripsi. Universitas Lampung. 58 hlm.

Umar, I. 2004. Pengolahan Tanah. Makalah Pribadi Falsafah Sains (PPS 702). Sekolah Pasca Sarjana/ S3. Institut Pertanian Bogor.

Utomo, M. 2006. Bahan baku pengelolaan lahan kering berkelanjuan. Universitas Lampung Bandar Lampung. $25 \mathrm{hlm}$.

Widiono, H. 2005. Pengaruh sistem olah tanah dan pertanaman terhadap erosi tanah. Jurnal Akta Agrosia. 8: 74-79. 